\title{
Influence of the Panama Seaway closure on large-scale ocean circulation and the tropical Pacific oxygen minimum zone during the Pliocene from model simulations
}

\author{
VYACHESLAV KHON ${ }^{1}$, BABETTE HOOGAKKER ${ }^{1}$, \\ BIRGIT SCHNEIDER ${ }^{2}$, JOACHIM SEGSCHNEIDER ${ }^{2}$ AND \\ WONSUN PARK ${ }^{3}$ \\ ${ }^{1}$ Heriot-Watt University \\ ${ }^{2}$ Kiel University \\ ${ }^{3}$ GEOMAR Helmholtz Centre for Ocean Research Kiel \\ Presenting Author: v.khon@hw.ac.uk
}

The world's largest oxygen minimum zone (OMZ) resides in the eastern tropical Pacific, where areas of high biological production collocate with poorly ventilated zones. The Pliocene epoch ( $\sim 5-2 \mathrm{Ma} \mathrm{BP})$ is considered to be a key period for the development of the tropical Pacific OMZ. The aim of this study is to explore influence of the Central American Seaway (CAS) closure on a large-scale ocean circulation and the development of the tropical Pacific OMZ during the Pliocene. The global climate model KCM was used in combination with biogeochemical model PISCES to study evolution of the tropical Pacific OMZ. We analyze a series of sensitivity experiments with the open/closed CAS under low and high atmospheric $\mathrm{CO} 2$ concentration. The physical fields from the aforementioned climate model simulations are used to force the biogeochemical model to obtain the oxygen distribution in the ocean. The Pliocene experiments reveal that the open CAS was associated with a weaker Atlantic Meridional Overturning Circulation (AMOC) due to influx of fresher Pacific water into the Atlantic. It is also hypothesized that the open CAS should have promoted oxygen enrichment in the Pacific Ocean during the Miocene by means of oxygen supply from the Atlantic. Therefore, in this study we will explore a potential role of a changed AMOC and the Pacific deep water circulation caused by the CAS closure in facilitating the tropical Pacific OMZ development. 